\title{
Effectiveness of Comprehensive Educational Package on Knowledge Regarding Promotion of Health and Prevention of Complication among Hypertensive Patients at Selected Hospital, Tamilnadu
}

\author{
Hema. $\mathbf{J}^{1}$, Karthi. $\mathbf{R}^{2}$ \\ ${ }^{1}$ M.Sc (N) E. S. College of Nursing, Villupuram, Tamilnadu \\ ${ }^{2}$ Professor cum Vice-Principal, E.S. College of Nursing, Villupuram, Tamilnadu \\ Corresponding Author: Karthi. R
}

\begin{abstract}
Aim: to assess the effectiveness of a comprehensive educational package on knowledge regarding promotion of health and prevention of complications among hypertensive patients.

Objectives: (i) To assess the pre and post test level of knowledge regarding promotion of health and prevention of complications among hypertensive patients. (ii) To evaluate the effectiveness of a comprehensive educational package on knowledge regarding promotion of health and prevention of complications among hypertensive patients. (iii) To find out the association between the post test level of knowledge on the promotion of health and prevention of complications with selected sociodemographic variables of patients with hypertension.
\end{abstract}

Methodology: A Pre experimental research design was carried out in this study. 60 samples were selected by using non-probability purposive sampling technique. The pre and post test level of knowledge was assessed by using structured knowledge questionnaires.

Results: The pre test mean was 11.5 with a standard deviation of 3.24 and the post test mean was 24.37 with a standard deviation of 2.98. The mean difference of pre and post test is 12.87; standard error is 0.29 . The ' $\mathrm{T}$ ' value is 44.37 is Highly Significant at $p<0.05$ it indicates that the knowledge level of hypertensive patients regarding promotion of health and prevention of complications was increased after the comprehensive educational package.

Conclusion: The study concluded that the level of knowledge among hypertensive patients is increased after giving a comprehensive educational package and it proved that a comprehensive educational package increases the level of knowledge.

Keys Words: Comprehensive educational package

\section{INTRODUCTION}

Hypertension is a condition in which the force of the blood against the artery walls becomes high. Usually, hypertension is defined as blood pressure above $130 / 80 \mathrm{~mm} . h \mathrm{~g}$. and considered severe if the pressure is above $180 / 120 \mathrm{~mm}$. hg. Hypertension is an invisible killer that rarely causes symptoms but is an important public health challenge because of its high prevalence and concomitant risk of coronary artery disease, heart failure, cerebrovascular diseases, and chronic renal failure.

High blood pressure is called the silent killer because it often has no warning signs or symptoms, and many people do not know they have it. Complications of hypertension are clinical outcomes that result from persistent elevation of blood pressure. Hypertension is a risk factor for all clinical manifestations of atherosclerosis. It 
is an independent predisposing factor for heart failure, coronary artery disease, stroke, kidney disease, and peripheral arterial disease. It is the most important risk factor for cardiovascular morbidity and mortality.

Complications affecting the heart left ventricular hypertrophy, hypertensive cardiomyopathy, and myocardial infarction. hypertensive heart disease is the result of structural and functional adaptations leading to left ventricular hypertrophy, diastolic dysfunction, abnormalities of blood flow due to atherosclerotic coronary artery disease and microvascular disease, and cardiac arrhythmias.

Complications affecting the brain hypertension are an important risk factor for brain infarction and hemorrhage. Approximately $85 \%$ of strokes are due to infarction and the remainder is due to haemorrhage, either intracerebral haemorrhage or subarachnoid haemorrhage. The incidence of stroke rises progressively with increasing blood pressure levels, particularly systolic blood pressure in individuals >65years. Treatment of hypertension convincingly decreases the incidence of both ischemic and hemorrhagic strokes.

Complications affecting the eye are hypertensive retinopathy is a condition characterized by a spectrum of retinal vascular signs in people with elevated blood pressure.

Hypertension is a risk factor for chronic kidney disease and end-stage kidney disease. The risk appears to be more closely related to systolic than diastolic blood pressure, and black men for developing ESRD at every level of blood pressure. Preventing high blood pressure: healthy living habits by living a healthy lifestyle, can help keep your blood pressure in a healthy range and lower your risk for heart disease and stroke.

\section{OBJECTIVES}

- To assess the pre and post test level of knowledge regarding promotion of health and prevention of complications among hypertensive patients.

- To evaluate the effectiveness of a comprehensive educational package on knowledge regarding promotion of health and prevention of complications among hypertensive patients.

- To find out the association between the post test level of knowledge on the promotion of health and prevention of complications with selected sociodemographic variables of patients with hypertension.

\section{HYPOTHESIS}

H1: There will be a significant increase in post test knowledge scores than the pre test knowledge score on the promotion of health and prevention of complications among hypertensive patients.

$\mathrm{H} 2$ : There will be a significant association between the post test level of knowledge on the promotion of health and prevention of complications with selected socio demographic variables of patients with hypertension.

\section{METHODOLOGY}

A Pre experimental research design study was carried out in this study. 60 samples were selected by using nonprobability purposive sampling technique. The pre and post test level of knowledge was assessed by using structured knowledge questionnaires.

\section{RESULT AND DISCUSSION}

Assessment of pre and post test pre and post test level of knowledge on the promotion of health and prevention of complications among hypertensive patients.

Table 4.2.1: Frequency and percentage distribution of pre test level of knowledge among hypertensive patients. $N=60$

\begin{tabular}{|l|l|l|}
\hline \multirow{2}{*}{ Level of Knowledge } & Frequency & Percentage \\
\cline { 2 - 3 } & $\mathbf{N}$ & $\mathbf{N \%}$ \\
\hline Inadequate Knowledge & 52 & $86.7 \%$ \\
\hline Moderate Knowledge & 7 & $11.7 \%$ \\
\hline Adequate Knowledge & 1 & $1.6 \%$ \\
\hline
\end{tabular}

Table 4.2.1 shows that pre test level of knowledge among 60 samples 52 $(86.7 \%)$ had inadequate Knowledge; 7 
Hema. J et.al. Effectiveness of comprehensive educational package on knowledge regarding promotion of health and prevention of complication among hypertensive patients at selected hospital, Tamilnadu.

(11.7\%) had moderate knowledge and $1 \quad(1.6 \%)$ had adequate knowledge.

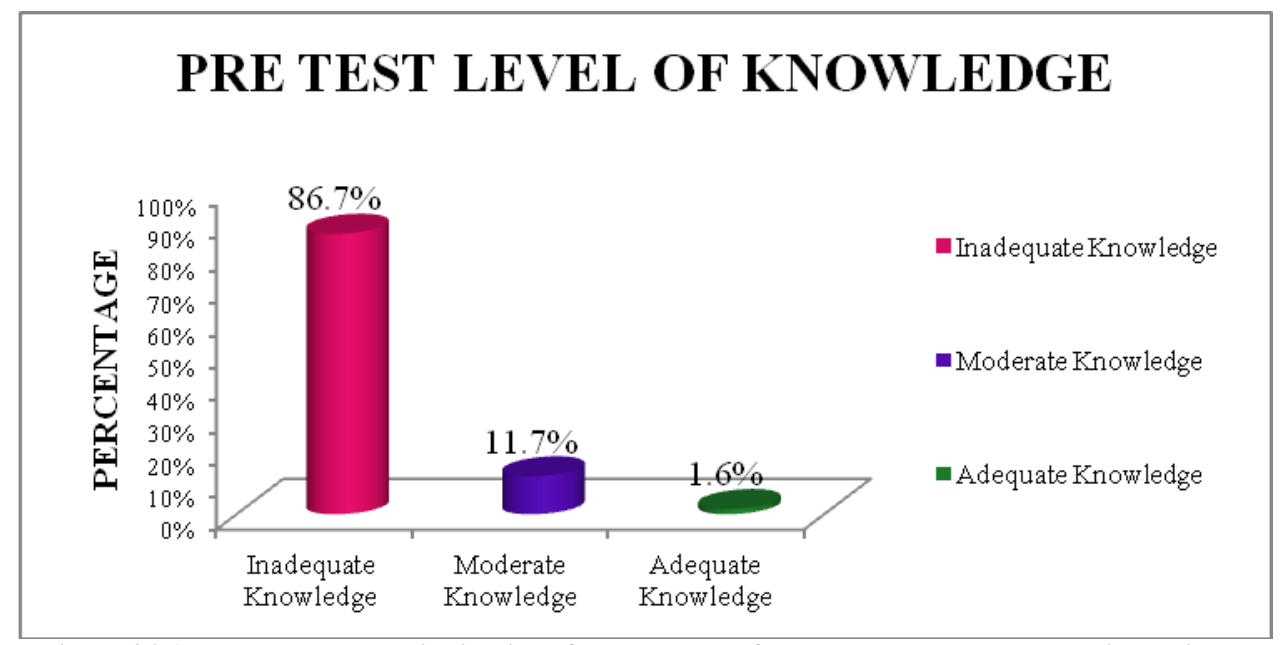

Figure 4.2.1 shows percentage distribution of pre test level of knowledge among hypertensive patients.

Table 4.2.2: frequency and percentage distribution of post test level of knowledge among hypertensive patients. $N=60$

\begin{tabular}{|l|l|l|}
\hline \multirow{2}{*}{ Level of Knowledge } & Frequency & Percentage \\
\cline { 2 - 3 } & $\mathbf{N}$ & $\mathbf{N} \%$ \\
\hline Inadequate knowledge & 0 & $0 \%$ \\
\hline Moderate knowledge & 17 & $28.3 \%$ \\
\hline Adequate knowledge & 43 & $71.7 \%$ \\
\hline
\end{tabular}

Table 4.2.2: shows that post test level of knowledge among 60 samples none of them had inadequate knowledge; $17(28.3 \% 0$ had moderate knowledge and 43 $(71.7 \%)$ had adequate knowledge.

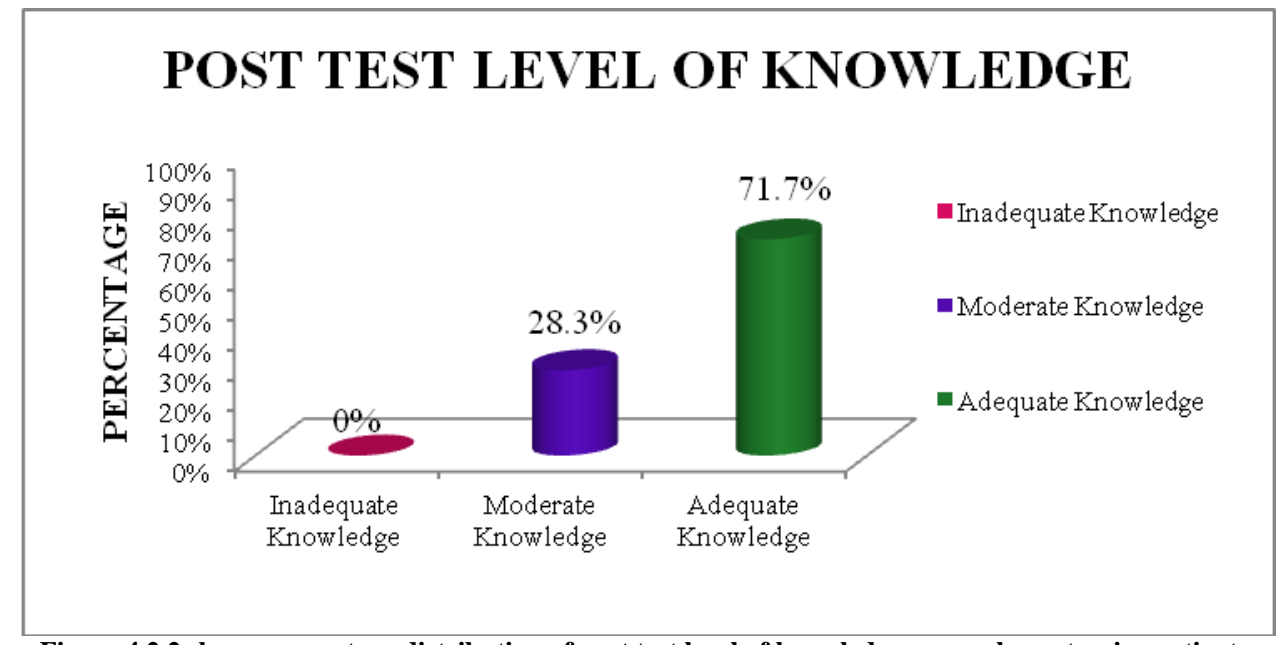

Figure 4.2.2 shows percentage distribution of post test level of knowledge among hypertensive patients.

Effectiveness of comprehensive educational package on knowledge regarding promotion of health and prevention of complications among hypertensive patients.

Table 4.3 Effectiveness of comprehensive educational package on knowledge regarding promotion of health and prevention of complications among hypertensive patients. $\quad \mathrm{N}=60$

\begin{tabular}{|l|l|l|l|l|l|l|}
\hline Pre test & \multicolumn{2}{|l|}{ Post test } & \multirow{2}{*}{ Mean difference } & \multirow{2}{*}{ Standard error } & ' $\mathbf{T}$ ' value \\
\hline Mean & Standard deviation & Mean & Standard deviation & & & \\
\hline 11.5 & 3.24 & 24.37 & 2.98 & 12.87 & 0.29 & $44.37 * \mathrm{HS}$ \\
\hline
\end{tabular}

Table 4.3 reveals that pre test mean was 11.5 with the standard deviation of 3.24 and the post test mean was 24.37 with the standard deviation of 2.98. The mean difference of pre and post test is 12.87; standard error is 0.29 . The ' $T$ ' value is 44.37 is Highly Significant at $\mathrm{p}<0.05$ it indicates that the knowledge level of hypertensive patients regarding promotion of health and prevention of complication was increased after the comprehensive educational package. Hence hypothesis $\mathrm{H} 1$ is accepted. 
Hema. J et.al. Effectiveness of comprehensive educational package on knowledge regarding promotion of health and prevention of complication among hypertensive patients at selected hospital, Tamilnadu.

Association between the post test level of knowledge on promotion of health and prevention of complications with selected socio demographic variables of Hypertensive patient.

Table 4.4.1 Association between the post test level of knowledge on promotion of health and prevention of complications with selected demographic variables Hypertensive patient. $\mathrm{N}=60$

\begin{tabular}{|c|c|c|c|c|c|c|}
\hline S. No & Demographic Variables & Inadequate & Moderate & Adequate & Chi square & p-value \\
\hline \multirow[t]{5}{*}{1} & Age of mother & & & & \multirow[t]{5}{*}{1.64} & \multirow{5}{*}{$\begin{array}{l}0.949 \\
\text { NS }\end{array}$} \\
\hline & a. $<40$ years & 0 & 1 & 7 & & \\
\hline & b. $41-50$ years & 0 & 6 & 17 & & \\
\hline & c. $51-60$ years & 0 & 7 & 14 & & \\
\hline & d. 61 and above & 0 & 3 & 5 & & \\
\hline \multirow[t]{3}{*}{2} & Sex & & & & \multirow[t]{3}{*}{0.99} & \multirow{3}{*}{$\begin{array}{l}0.61 \\
\text { NS }\end{array}$} \\
\hline & a. Male & 0 & 10 & 31 & & \\
\hline & b. Female & 0 & 7 & 12 & & \\
\hline \multirow[t]{6}{*}{3} & Educational qualification & & & & \multirow[t]{6}{*}{34.22} & \multirow{6}{*}{$\begin{array}{l}0.000037 \\
S^{*}\end{array}$} \\
\hline & a. Illiterate & 0 & 7 & 0 & & \\
\hline & b. Primary & 0 & 7 & 4 & & \\
\hline & c. High school & 0 & 1 & 12 & & \\
\hline & d. Higher secondary & 0 & 2 & 15 & & \\
\hline & e. Graduate & 0 & 0 & 12 & & \\
\hline \multirow[t]{5}{*}{4} & Occupation & & & & \multirow[t]{5}{*}{5.92} & \multirow{5}{*}{$\begin{array}{l}0.43 \\
\mathrm{NS}\end{array}$} \\
\hline & a. Agriculture & 0 & 3 & 11 & & \\
\hline & b. Business & 0 & 7 & 10 & & \\
\hline & c. Profession & 0 & 2 & 16 & & \\
\hline & d. Un employee & 0 & 5 & 6 & & \\
\hline \multirow[t]{3}{*}{5} & Residence & & & & \multirow[t]{3}{*}{0.287} & \multirow{3}{*}{$\begin{array}{l}0.866 \\
\text { NS }\end{array}$} \\
\hline & a. Urban & 0 & 7 & 21 & & \\
\hline & b. Rural & 0 & 10 & 22 & & \\
\hline \multirow[t]{6}{*}{6} & Family monthly income & & & & \multirow[t]{6}{*}{0.482} & \multirow{6}{*}{$\begin{array}{l}0.998 \\
\text { NS }\end{array}$} \\
\hline & a. $<$ Rs.5000 & 0 & 0 & 0 & & \\
\hline & b. Rs 5000- Rs 10000 & 0 & 0 & 0 & & \\
\hline & c. Rs $10001-$ Rs 15000 & 0 & 1 & 1 & & \\
\hline & d. Rs $15001-$ Rs 20000 & 0 & 9 & 24 & & \\
\hline & e. > Rs 20000 & 0 & 7 & 18 & & \\
\hline \multirow[t]{5}{*}{7} & Source of information & & & & \multirow[t]{5}{*}{1.927} & \multirow{5}{*}{$\begin{array}{l}0.926 \\
\text { NS }\end{array}$} \\
\hline & a. Health Worker & 0 & 7 & 23 & & \\
\hline & b. Family Members & 0 & 7 & 10 & & \\
\hline & c. Mass media & 0 & 3 & 10 & & \\
\hline & d. friends & 0 & 0 & 0 & & \\
\hline
\end{tabular}

Table 4.4.1 shows that there is significant association between the post test level of knowledge and educational qualification and there is no significant association between the Age, Sex, Occupation, Residence, Family Monthly income and Source of Information.

\section{DISCUSSION}

Frequency and percentage distribution of hypertensive patients according to their Demographic and clinical variables

Frequency and percentage distribution of demographic variables of hypertensive patients among 60 samples majority of them $23(38.4 \%)$ were in age group of $41-50$ years; $41(68.3 \%)$ were Male; $19(31.7 \%)$ were studied Higher Secondary; $18(30 \%)$ were professional workers; 32(53.3\%) were lives in Rural; 33 (55\%) were belongs to Rs 15001- Rs20000; $30(50 \%)$ were got information through Health Workers.

Frequency and percentage of distribution of clinical variables of hypertensive patients among 60 samples majority of them $23(38.3 \%)$ were in $>5$ years of duration of illness; $45(75 \%)$ were has no family history of hypertension; 58 $(96.6 \%)$ were under regular treatment; $36(60 \%)$ were had no comorbidities; $50(83.3 \%)$ were has no any bad habits; $28(46.7 \%)$ were performing physical exercise for sometimes.

The first objective of the study is to assess the pre and post test level of knowledge regarding promotion of health and prevention of complication among hypertensive patients. 
The pre test level of knowledge among 60 hypertensive patients $52(86.7 \%)$ had inadequate Knowledge 7 (11.7\%) had moderate knowledge and $1(1.6 \%)$ had adequate knowledge. The post test level of knowledge among 60 hypertensive patients none of them had inadequate knowledge $17(28.3 \%)$ had moderate knowledge and 43 $(71.7 \%)$ had adequate knowledge.

The second objective of the study to evaluate the effectiveness of comprehensive educational package on knowledge regarding promotion of health and prevention of complications among hypertensive patients

The pre test mean was 11.5 with the standard deviation of 3.24 and the post test mean was 24.37 with the standard deviation of 2.98. The mean difference of pre and post test is 12.87; standard error is 0.29 . The ' $\mathrm{T}$ ' value is 44.37 is Highly Significant at $p<0.05$ it indicates that the knowledge level of hypertensive patients regarding promotion of health and prevention of complication was increased after the comprehensive educational package. Hence hypothesis $\mathrm{H} 1$ is accepted.

The third objective of the study is to find out the association between the post test level of knowledge on promotion of health and prevention of complications with selected socio demographic and clinical variables

In demographic variables there was a significant association between the post test level of knowledge and educational qualification with the chi square value 34.22 ; p-value is 0.000037 and there is no significant association between the Age, Sex, Occupation, Residence, Family Monthly income and Source of Information.

In clinical variables there is significant association between the post test level of knowledge and habit of hypertensive patient's chi square value 49.66; p-value is 0.00001 and there is no significant association between the Duration of illness, Family history, Comorbidities, Performing Physical Exercise. Hence hypothesis $\mathrm{H} 2$ is accepted.

\section{CONCLUSION}

The findings of the study show that among hypertensive patients the knowledge scores of pre test mean was 11.5 with the standard deviation of 3.24 and the post test mean was 24.37 with the standard deviation of 2.98. The mean difference of pre and post test is 12.87; standard error is 0.29 . The ' $\mathrm{T}$ ' value is 44.37 is Highly Significant at $\mathrm{p}<0.05$ it indicates that the knowledge level of hypertensive patients regarding promotion of health and prevention of complication was increased after the comprehensive educational package. The study concluded that the level of knowledge among hypertensive patients are increased after giving comprehensive educational package and its proved that comprehensive educational package increases the level of knowledge.

\section{Acknowledgement: None}

Conflict of Interest: None

\section{Source of Funding: None}

Ethical Approval: Approved

\section{REFERENCES \\ BOOK REFERENCE}

1. Agarval, L. P (2006). Medical Surgical Nursing. (1st edition). New Delhi: Jaypee Brothers Medical Publishers.

2. Basavanthappa, B. T. (2009). Medical Surgical Nursing. (2nd edition). New Delhi: Jaypee Brothers Medical Publishers.

3. Basvanthappa, B. T. (2007). Nursing Theories. (1st edition). New Delhi: Jaypee Brothers Medical Publishers.

4. Black, J. M and Jacobs, E. M. (2006). Medical Surgical Nursing. (5th edition). Philadelphia: W.B. Saunders Company.

5. Holloway, N.M.(1999). Medical Surgical Nursing Care Planning. (3rd edition). Pennsylvania: Spring house publishers.

6. Ignastsvicius, D.D. \& Linda. W. (2004). Text Book of Medical Surgical Nursing. (4th edition) Philadelphia: W.B. Saunders Company.

7. Janice M Morse. (2004). Nursing Research the Application of Quantitative Approaches. 
Hema. J et.al. Effectiveness of comprehensive educational package on knowledge regarding promotion of health and prevention of complication among hypertensive patients at selected hospital, Tamilnadu.

(2nd edition). United Kingdom: Nelson Thomas Publications.

8. John W Best and James V Khan. (2003). Research in Education. (17th edition). New Delhi: Asoka Publications.

9. Lewis, S.M. et.al. (2006). Medical Surgical Nursing. (7th edition). London: Mosby Publications.

10. Martha. et.al. (2003). Nursing Theory Utilization and Application. (2nd edition). Chicago: Lippincott Publishers

11. Mahajan, B.K. (2007). Methods in Biostatistics. (6th edition). New Delhi: Jaypee Brothers.

12. Merlin, E.P (2007). Nursing Theories and Nursing Practice. (1st edition) New Delhi: Jaypee Publication.

13. Shafer's. (2004). Medical Surgical Nursing. (7th edition). New Delhi: B.I. Publication.

14. Varma, B.L \& Sukla, G.D. (2004). Biostatistics Perspective in Health Care Research and Practice. (5th edition). New Delhi: CBS Publication.

15. Wayne, W, Daniel. (2004). Biostatistics A Founder For Analysis in Health Science. (7th edition). New Delhi: Pushpa Prince Service.

\section{JOURNAL REFERENCE}

1. Bollampally M, Chandershekhar P, Kumar KP, Surakasula A, Srikanth S, Reddy TRM. Assessment of patient's knowledge, attitude and practice regarding hypertension. International Journal of Research in Medical Sciences; 2016;4:3299-304.

2. Kongarasan P, Shah PB. Knowledge and perception of hypertension among hypertensive patients attending rural health and training centre, department of community medicine, SRMC \& RI. International Journal of Community Medicine and Public Health; 2018;5:2323-6.

3. Raghdaa Sadeq, Riyadh K Lafta, Knowledge, attitude and practice about hypertension in hypertensive patients attending hospitals in Baghdad, Iraq, South East Asia Journal Of Public Health; 2017;7(1):29-34.

4. YathiKumaraSwamy Gowda, Ashok Nayak, Aldrin vas A Descriptive Study to Assess the Knowledge Regarding Prevention of Complications of Hypertension Among Hypertensive Patients of Selected Hospitals of Moodbidri with a View to Provide an Informational Pamphlet, Journal of Biology, Agriculture and Healthcare; 2018; 8(21):1012

5. Addisu Taye Abate, Netsanet Bayu and Tesfamichael G.Mariam, Hypertensive Patients' Knowledge of Risk Factors and Warning Signs of Stroke at Felege Hiwot Referral Hospital, Northwest Ethiopia: A Cross-Sectional Study; Hindawi Neurology Research International journal; 2019, Article ID 8570428, 7 pages

How to cite this article: Hema. J, Karthi. R. Effectiveness of comprehensive educational package on knowledge regarding promotion of health and prevention of complication among hypertensive patients at selected hospital, Tamilnadu. Galore International Journal of Applied Sciences \& Humanities. 2021; 5(3): 14-19. DOI: https://doi.org/10. 52403/gijash.20210702 